\title{
SYNTHESIS AND DETERMINATION OF THE PROPERTIES OF THE BIFUNCTIONAL BETA ZEOLITE CATALYSTS FOR N-HEPTANE HYDROISOMERIZATION
}

\author{
GOODARZ TALEBI ${ }^{A}$, MORTEZA SOHRABI*A, RIITTA L. KEISKI ${ }^{B}$, MIKA HUUHTANEN ${ }^{B}$, SEID J. ROYAEE ${ }^{A}$, \\ SAEED MAGHSOUDIC, HAMID IMAMVERDIZADEHA \\ ${ }^{a}$ Chemical Engineering Faculty, Amirkabir University of Technology, Tehran, Iran. \\ ${ }^{b}$ Department of Process and Environmental Engineering, University of Oulu, POB 4300, FIN-90014 University of Oulu, Finland. \\ ${ }^{c}$ Chemical Engineering Faculty, Iran University of Science and Technology, Tehran, Iran. \\ (Received: 3 July 2007 - Accepted: 4 December 2007)
}

\begin{abstract}
In this study, two types of beta zeolites with different $\mathrm{Si} / \mathrm{Al}$ ratios (11.7 and 24.5) were synthesized hydrothermally using tetraethylammonium hydroxide (TEAOH) as the template. Different amounts of Platinum $(0.2 \%, 0.5 \%$ and $1.2 \%)$ were loaded on the protonated form of zeolite by incipient wet impregnation method with hexachloroplatinic acid in $0.2 \mathrm{~N} \mathrm{Cl}^{-}$progressive ion solutions. Catalytic reactions were carried out at atmospheric pressure in a fixed bed reactor with vertical placing and downward flow at three different temperatures, various WHSV (weight hourly space velocity) and n- $\mathrm{H}_{2} / \mathrm{n}-\mathrm{HC}$ (molar hydrogen / hydrocarbon) ratio $\left(230,250,280{ }^{\circ} \mathrm{C}, 1.64,2.48,3.28 \mathrm{hr}^{-1}\right.$ and $6,10,14$ respectively). Increasing the $\mathrm{Si} / \mathrm{Al}$ ratio from 11.7 to 24.5 promoted the selectivity and yield. It was found that optimum platinum content depends on the $\mathrm{Si} / \mathrm{Al}$ ratio (zeolite acidity) present in the zeolite catalyst. The monobranched to dibranched isomers ratio were correlated with a linear function of n-heptane conversion. Such a correlation was found to be valid for various $\mathrm{Si} / \mathrm{Al}$ ratios, metal content, processing temperature and pressure, WHSV and hydrogen to hydrocarbon ratio. This observation may indicate that in isomerization reactions, the mono-branched isomers are first produced but subsequently transformed into multi-branched isomers.
\end{abstract}

Keywords: Hydroisomerization, Beta zeolite, Bifunctional catalysts , n-Heptane

\section{INTRODUCTION}

As the environmental constrain concerning the gasoline used in vehicles becomes tougher, isomerate consisting mainly of iso-paraffins appears as a promising substitute for conventional gasoline blendstock in view of Reid vapor pressure, RON, olefin and aromatic contents' regulations ${ }^{1}$. The isomerization of normal alkanes into branched isomers in order to meet the restrictions and enhancing the octane quality of gasoline has been the subject of intensive investigations ${ }^{2-6}$.

One of the most important fractions of naphtha is n-heptane. Owing to the low octane number, it is separated and diverted to CCR (Continuous Catalyst Regeneration) unit, where hydrocracking occurs under severe conditions, leading to some portion to light hydrocarbons gaseous. Thus, hydroisomerization of nheptane to mono and multi branched isomers is obviously an important issue worth to be studied.

It has been shown that certain types of zeolites could be promising catalysts in skeletal isomerization of alkanes. As an example, n-heptane isomerization has been carried out using $\mathrm{WO}_{\mathrm{x}}-\mathrm{ZrO}_{2}{ }^{7}, \mathrm{SO}_{4}{ }^{2-} / \mathrm{ZrO}_{2}{ }^{8}, \mathrm{ZSM}-5{ }^{9}$, Y zeolite ${ }^{2,9}, \mathrm{Pt} /$ Mor $^{10}$, SAPO ${ }^{11,12}$ and Beta zeolites ${ }^{7,13-15}$ catalysts. Alkane Hydroisomerization has been also investigated applying a bifunctional zeolite catalyst. It has been shown that the rate of reaction according to metal-acid mechanism (Weisz bifunctional mechanism, Scheme-1) has an order close to -1 with respect to hydrogen ${ }^{16-18}$.

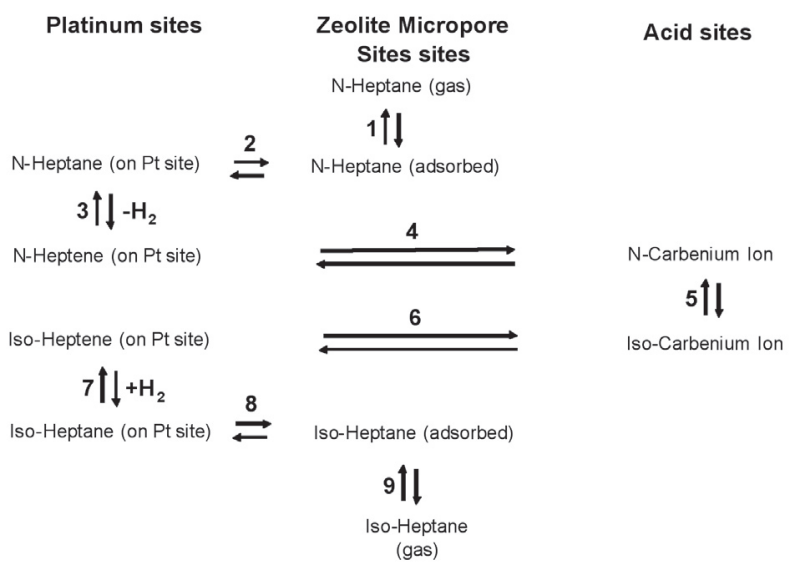

Scheme 1: Weisz mechanism for n-alkane hydroisomerization
Pore geometry, pore size distribution, acid property (Lewis \& Bronsted sites), strength and distribution of acid sites, number of acidic sites and hydrogenation / dehydrogenation ability of metals are the key factors in zeolitic bifunctional catalyst performance. In n-heptane hydroisomerization, the Pt-loaded three dimensional 12-MR Beta was observed to have a higher conversion and selectivity than those of the one dimensional Pt-Mor catalysts 3 .

In order to formulate and define the Pt-Beta synthesis procedure, six samples having different $\mathrm{Si} / \mathrm{Al}$ ratios and Pt contents were prepared and tested. In addition, the impacts of processing parameters such as WHSV, $\mathrm{n}-\mathrm{H}_{2} / \mathrm{n}-\mathrm{HC}$ ratio and temperature on conversion, selectivity and isomer distribution have been studied.

\section{EXPERIMENTAL}

\section{Catalyst Preparation}

The Beta catalysts used in this study were synthesized hydrothermally using tetraethylammonium hydroxide (TEAOH) as the template. About 0.53 $\mathrm{g}$ of sodium chloride with $1.44 \mathrm{~g}$ potassium chloride were added to $179.2 \mathrm{~g}$ of tetraethylammonium hydroxide solution (TEAOH, Fluka, $40 \mathrm{wt} \%$ aqueous solution) and the mixture was stirred for 10 minutes. Subsequently, $29.54 \mathrm{~g}$ of Aerosil (Silica source, Degussa 380, 99+\%) was added to the mixture with vigorous stirring (Solution $\mathrm{A}$ ). In the next step, $0.33 \mathrm{~g}$ of sodium hydroxide and $(1.7 \mathrm{~g}, 3.45 \mathrm{~g})$ of sodium aluminate were dissolved in $5 \mathrm{~g}$ of deionized water (Solution B). Solution B was added dropwise to solution A with continuous stirring until a uniform solution was formed ${ }^{19}$. The homogenized gel was then loaded into a PTFE lined autoclave. The autoclave was sealed with a stainless steel cover and placed into a rotary oven. Heating was provided for 48 hours at $140{ }^{\circ} \mathrm{C}$ (at $60 \mathrm{rpm}$ ). The crystallization process was terminated by quenching the autoclave in the cold water. The synthesized powders were recovered by centrifugation. The powders were washed with hot deionized water for several times so that the $\mathrm{pH}$ of rinsed water decreased to about 9 . The washed powders were dried at $100{ }^{\circ} \mathrm{C}$ during overnight. In order to remove the organic components present in the powders, the latter was calcined at $550{ }^{\circ} \mathrm{C}$ for 2 hours in nitrogen atmosphere and continued for further $2 \mathrm{~h}$ in air. Zeolites with ammonia content were prepared by cation exchange process using $0.3 \mathrm{~N} \mathrm{NH}_{4} \mathrm{Cl}$ solution at $80{ }^{\circ} \mathrm{C}$. Such a process was repeated two times. $\mathrm{NH}_{4}$-Beta forms of zeolite was washed with deionized water and dried at $70{ }^{\circ} \mathrm{C}$ during overnight. Ammonia was then removed from the zeolite by heating at $550{ }^{\circ} \mathrm{C}$ for 4 hours yielding $\mathrm{H}$-Beta zeolite. 
Platinum was loaded on the protonated form of zeolite by incipient wet impregnation method using hexachloroplatinic acid in $0.2 \mathrm{~N} \mathrm{Cl}^{-}$progressive ion solutions. The apparatus was a rotary evaporator operating at $250 \mathrm{mmHg}$ vacuum and $70{ }^{\circ} \mathrm{C}$ for 4 hours $(60 \mathrm{rpm})$. The impregnated catalysts were dried overnight at $120{ }^{\circ} \mathrm{C}$ and oxidized for 4 hours at $400{ }^{\circ} \mathrm{C}$. Finally, catalysts were reduced in situ before being applied in the reaction studies.

\section{Catalyst Characterization}

Powders' X-ray diffraction (XRD) patterns were obtained using a Philips (model PC-APD) diffractometer applying $\mathrm{Cu} \mathrm{K \alpha}$ radiation at $40 \mathrm{kV}$ and $30 \mathrm{~mA}$ (Figure 1: $a$ and $b$ ).

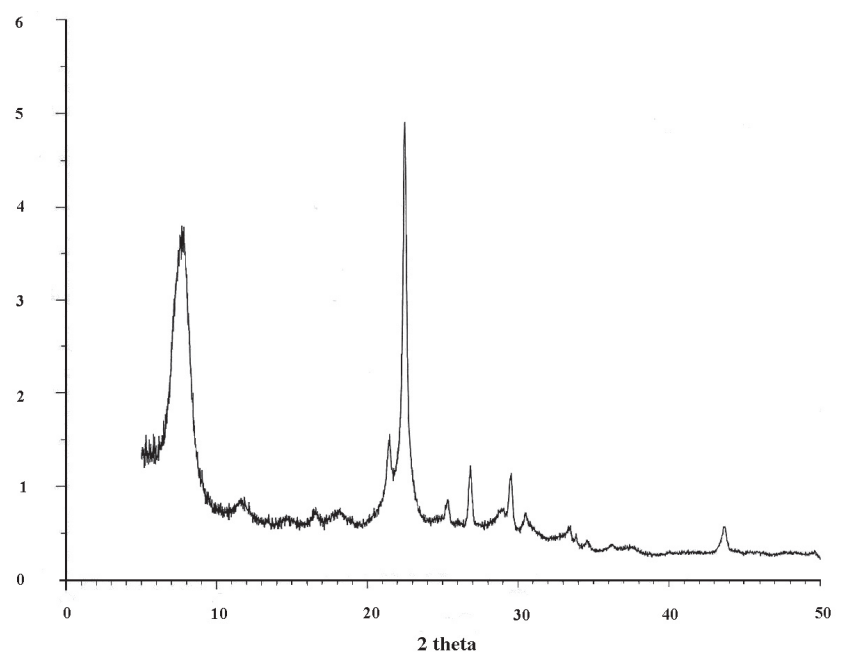

(a)

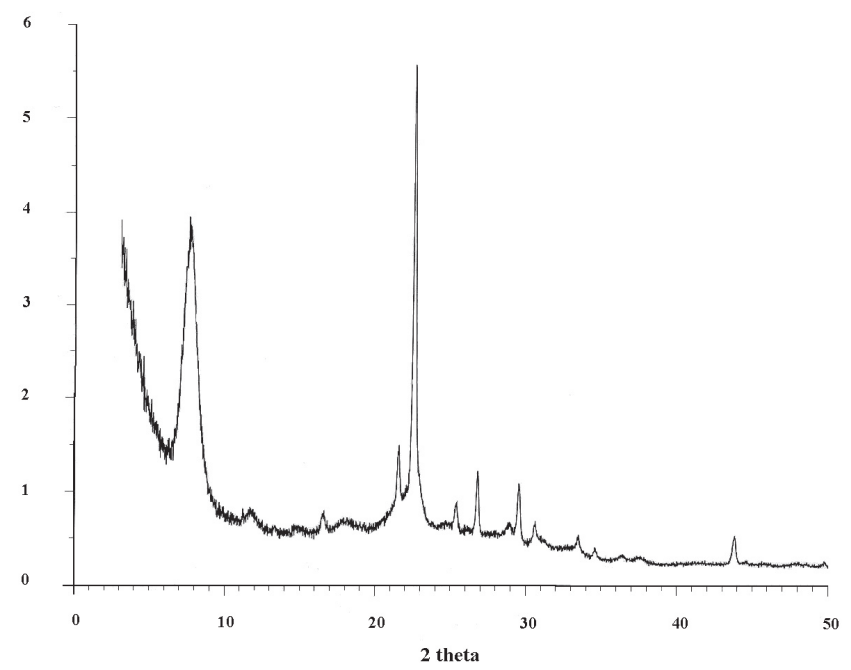

(b)

Figure 1: a) XRD Pattern $\beta$ (11.65) and b) XRD Pattern $\beta$ (24.5).

Temperature programmed desorption (TPD) was carried out using MICROMERITICS 2900 TPD/TPR. Protonated zeolite samples were flushed by inert gas $(\mathrm{He})$ with $30 \mathrm{ml} / \mathrm{min}$ flow rate for about $45 \mathrm{~min}$ at $500{ }^{\circ} \mathrm{C}$. Samples were cooled to $100^{\circ} \mathrm{C}$ by passing ammonia over the latter for 30 minutes with a flow rate of $30 \mathrm{ml} / \mathrm{min}$. An inert gas was applied to remove the physisorbed ammonia molecules. In case of TPD experiments, the samples were heated from $100{ }^{\circ} \mathrm{C}$ to $500{ }^{\circ} \mathrm{C}$ with a rate of $10{ }^{\circ} \mathrm{C} / \mathrm{min}$ and the desorbing species were monitored and measured simultaneously using a TCD detector. Results of the acidity measurements are summarized in Table 1 and those of ammonia TPD are shown in figure 2 .

Table 1. Acids strength and distribution in two zeolite samples.

\begin{tabular}{|c|c|c|c|}
\hline $\begin{array}{c}\text { Zeolite } \\
\text { Sample }\end{array}$ & $\begin{array}{c}\text { Total acid } \\
(\mu \mathrm{mol} / \mathrm{gr})\end{array}$ & $\begin{array}{c}\text { Weak acid } \\
\left(\mu \mathbf{m o l} / \mathbf{g r}\left({ }^{\circ} \mathbf{C}\right)\right)\end{array}$ & $\begin{array}{c}\text { Strong acid } \\
\left(\mu \mathbf{m o l} / \mathbf{g r}\left({ }^{\circ} \mathbf{C}\right)\right)\end{array}$ \\
\hline$\beta(11.65)^{\mathrm{A} 0}$ & 862 & $653(197)$ & $209(363)$ \\
\hline$\beta(24.5)^{\mathrm{B} 0}$ & 786 & $591(196)$ & $191(358)$ \\
\hline
\end{tabular}

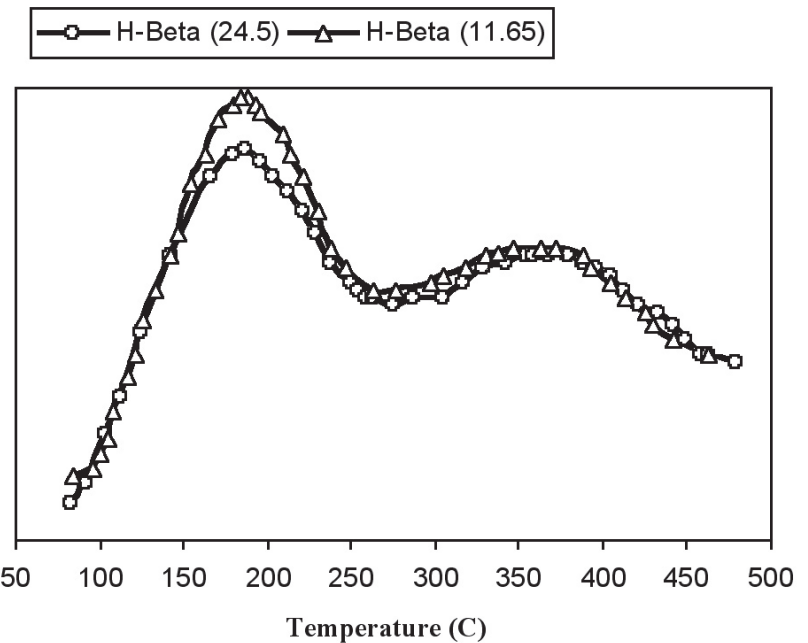

Figure 2: NH3 TPD of two zeolite samples.

The pre-treatment procedure for measurement of specific surface area and Pt dispersion by $\mathrm{N}_{2}$ adsorption at $-196^{\circ} \mathrm{C}$ and $\mathrm{CO}$ chemisorption respectively, was carried out by heating the samples in vacuum to $100^{\circ} \mathrm{C}$ with a rate of $10^{\circ} \mathrm{C} /$ $\mathrm{min}$ and leaving the latter in vacuum for further 30 minutes at this temperature. The sample was then heated to $350^{\circ} \mathrm{C}$ and evacuation was continued at this temperature for more 3 hours. The sample was then cooled to room temperature. The results are summarized in Table 2.

Table 2. Chemical properties of catalyst samples.

\begin{tabular}{|c|c|c|c|c|c|c|c|c|}
\hline Catalyst Sample & A0 & A1 & A2 & A3 & B0 & B1 & B2 & B3 \\
\hline Si/Al Ratio & 11.65 & 11.65 & 11.65 & 11.65 & 24.5 & 24.5 & 24.5 & 24.5 \\
\hline $\begin{array}{c}\text { Pt Content } \\
\text { (wt\%) }\end{array}$ & 0 & 0.2 & 0.7 & 1.2 & 0 & 0.2 & 0.7 & 1.2 \\
\hline $\begin{array}{c}\text { Surface Area } \\
\left(\mathbf{m}^{2} / \mathbf{g r}\right)\end{array}$ & 644 & 633 & 626 & 618 & 603 & 602 & 602 & 601 \\
\hline $\begin{array}{c}\text { Total Acidity } \\
\text { (mmol H+/gr) }^{\mathrm{a}}\end{array}$ & 862 & - & - & - & 786 & - & - & - \\
\hline $\begin{array}{c}\text { Metal dispersion } \\
(\%)\end{array}$ & - & 77.4 & 48.3 & 31.9 & - & 61.7 & 33.6 & 14.6 \\
\hline
\end{tabular}

a) by Temperature programmed desorption

b) by $\mathrm{CO}$ chemisorption

The TEM experiments were performed applying Energy-Filtered Transmission Electron Microscopy (EFTEM) Leo 912 Omega. The sample was mixed with acetone and stirred. A drop of suspension was set on the $\mathrm{Cu}-$ gauze and inserted in a high vacuum chamber. The TEM images were taken with a magnification of 100000 (figures 3 and 4). 

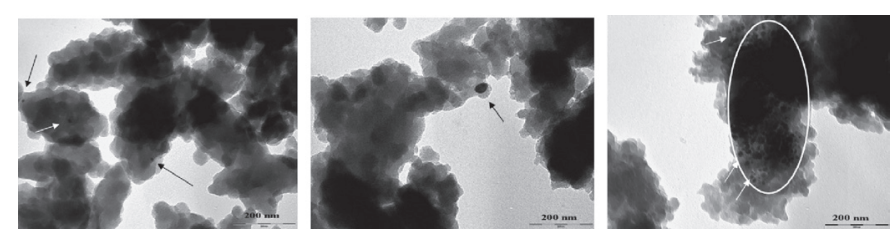

Figure 3: TEM results for prepared catalysts $(\mathrm{Si} / \mathrm{Al}=11.65) \mathrm{Pt}$ is shown by arrows (magnification: 100000).
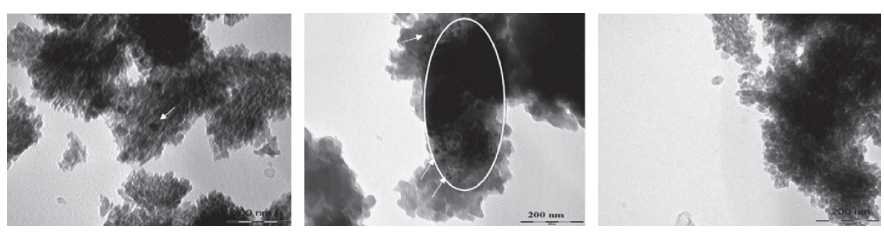

Figure 4: TEM results for prepared catalysts $(\mathrm{Si} / \mathrm{Al}=24.5)$,. Pt is shown by arrows (magnification: 100000).

\section{Catalytic Reaction}

The catalytic reactions were studied at atmospheric pressure using a 10 $\mathrm{mm}$ id tubular reactor with vertical placing and downward flow packed with 1 $\mathrm{g}$ of a catalyst sample. The liquid reactant (n-heptane, Panerac 99+\%) was fed to the reactor by a high performance liquid chromatography (HPLC) pump. The hydrogen and nitrogen flow-rates were controlled by two digital mass flow controllers (MFC, Brooks Co. Instrumentation). Reaction products were analyzed, using an Agilent model $6890 \mathrm{~N}$ gas chromatograph equipped with a flame ionization detector, HP-PONA $(50 \mathrm{~m} \times 0.2 \mathrm{~mm})$ capillary column and an automatic sampling valve. The reactor outlet was conducted to the automatic sampling valve through a line at $150{ }^{\circ} \mathrm{C}$ with an electric heater wrapped around the latter in order to prevent condensation. Prior to catalytic reaction the fresh catalyst was reduced at $400{ }^{\circ} \mathrm{C}$ using hydrogen with a flowrate of $40 \mathrm{ml} / \mathrm{min}$. $\mathrm{g}$ for 4 hours. Catalytic tests were performed at a temperature range of 230 to $280{ }^{\circ} \mathrm{C}$. The temperature was measured with two thermocouples placed in the catalyst bed and the furnace, respectively. The temperature control $\left(-/+0.5^{\circ} \mathrm{C}\right)$ was achieved using a temperature controller. The effects of WHSV and n- $\mathrm{H}_{2} / \mathrm{n}-$ $\mathrm{HC}$ ratio on the catalysts performance were investigated within the ranges of 1.64 to $3.28 \mathrm{~h}^{-1}$ and 6 to 14 respectively.

Conversion, selectivity and yield were calculated using the following equations. In these relations subscripts 0 and $\mathrm{f}$ denote initial and final weights, respectively, and $\mathrm{j}$ relates to all $\mathrm{C} 7$ isomers.

$$
\begin{gathered}
\text { Conv.C7 }(\%)=\frac{(n C 7)_{0}-(n C 7)_{f}}{(n C 7)_{0}} \times 100 \\
\text { Sel.iC7 }(\%)=\frac{\sum_{j}\left[\left(i C 7_{j}\right)_{f}-\left(i C 7_{j}\right)_{0}\right]}{(n C 7)_{0}-(n C 7)_{f}} \times 100 \\
\text { YieldiC7 }(\%)=\text { Conv.C7 } \times \text { Sel.iC } 7=\frac{\sum_{j}\left[\left(i C 7_{j}\right)_{f}-\left(i C 7_{j}\right)_{0}\right]}{(n C 7)_{0}} \times 100
\end{gathered}
$$

\section{RESULTS AND DISCUSSIONS}

Effects of reaction conditions on $n$-heptane conversion and iso-heptane selectivity and yield

Regarding the results for $\mathrm{n}$-heptane conversions at various temperatures for all catalyst samples (Figs. 5-13), it may be observed that with increasing reaction temperature, $\mathrm{n}$-heptane conversion is also enhanced while iso-heptane selectivity decreased.

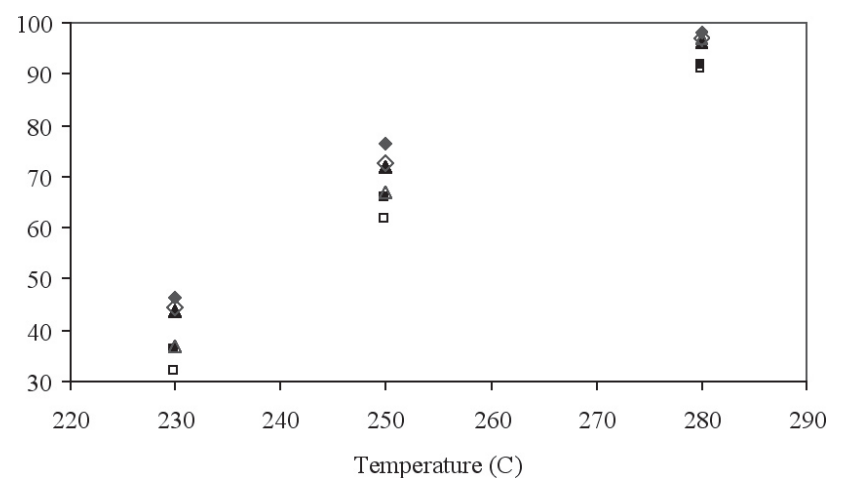
$\mathrm{HC}=6$

Figure 5: $\mathrm{n}-\mathrm{Heptane}$ conversion vs. temperature WHSV $=1.64, \mathrm{n}-\mathrm{H}_{2} / \mathrm{n}-$

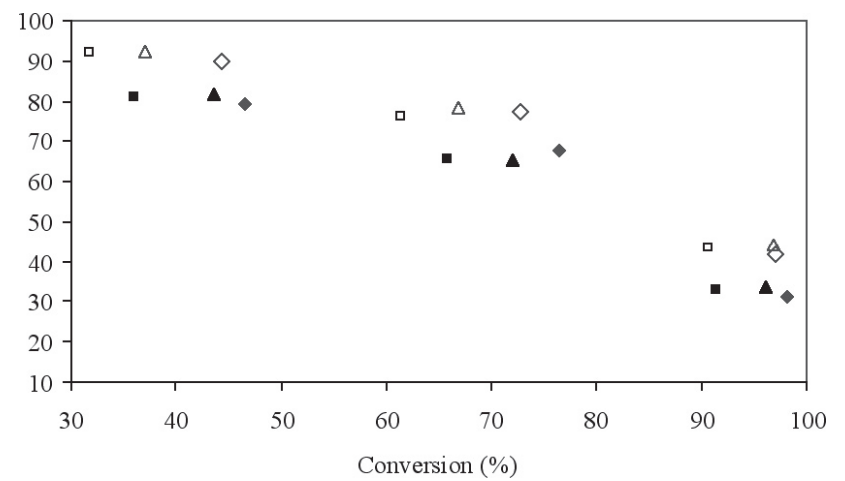

Figure 6: Iso-heptane selectivity vs. n-heptane conversion $\mathrm{WHSV}=1.64$, $\mathrm{n}-\mathrm{H}_{2} / \mathrm{n}-\mathrm{HC}=6$

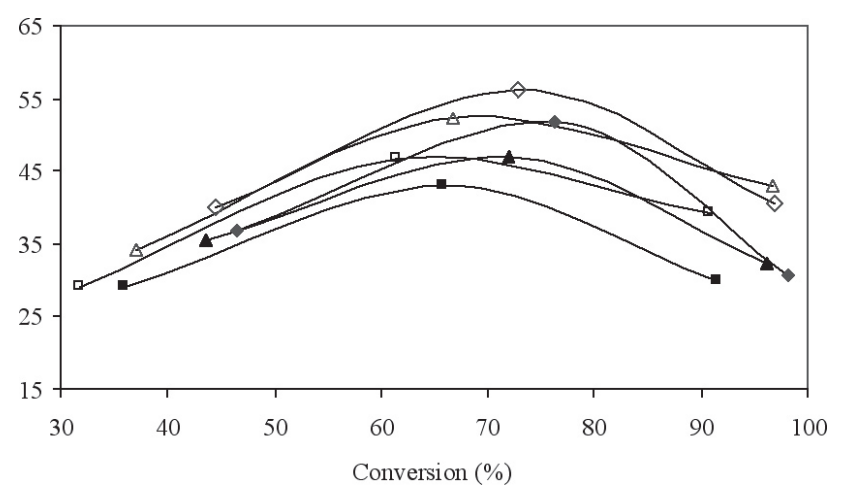

Figure 7: Iso-heptane yield vs. n-heptane conversion WHSV=1.64, n- $\mathrm{H}_{2} /$ $\mathrm{n}-\mathrm{HC}=6$

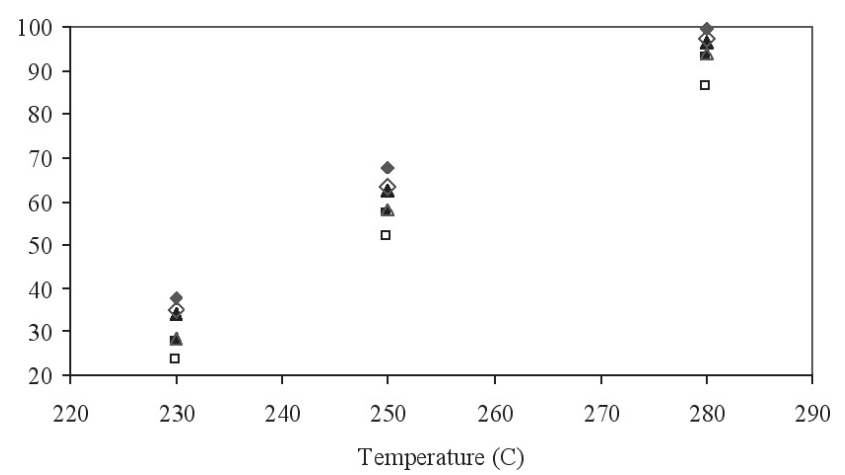
$\mathrm{HC}=6$

Figure 8: $\mathrm{n}-\mathrm{Heptane}$ conversion vs. temperature WHSV $=2.46, \mathrm{n}-\mathrm{H}_{2} / \mathrm{n}-$ 


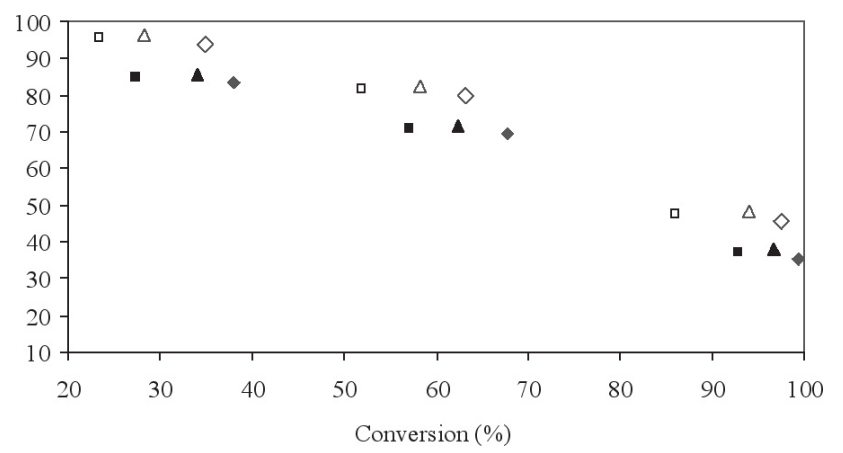

Figure 9: Iso-heptane selectivity vs. $n$-heptane conversion $\mathrm{WHSV}=2.46$, $\mathrm{n}-\mathrm{H}_{2} / \mathrm{n}-\mathrm{HC}=6$

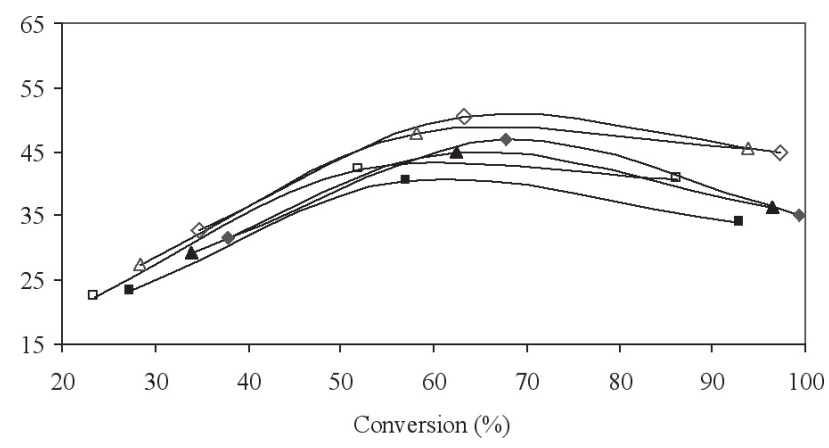

Figure 10: Iso-heptane yield vs. $\mathrm{n}$-heptane conversion $\mathrm{WHSV}=2.46, \mathrm{n}-$ $\mathrm{H}_{2} / \mathrm{n}-\mathrm{HC}=6$

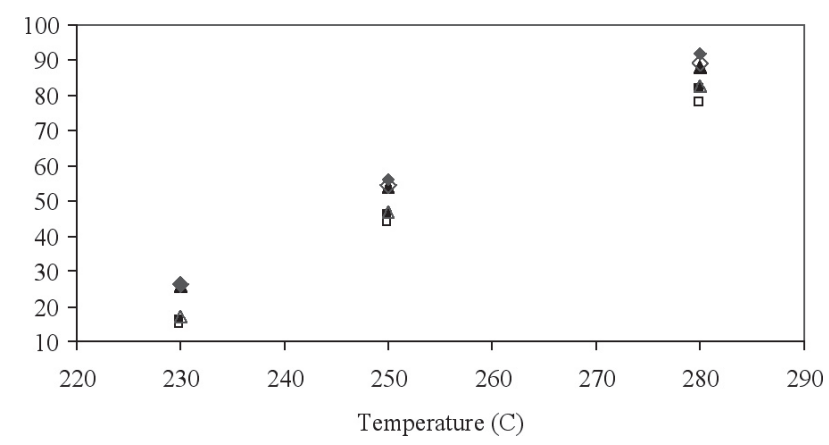
$\mathrm{HC}=6$

Figure 11: n-Heptane conversion vs. temperature $\mathrm{WHSV}=3.28, \mathrm{n}-\mathrm{H}_{2} / \mathrm{n}-$

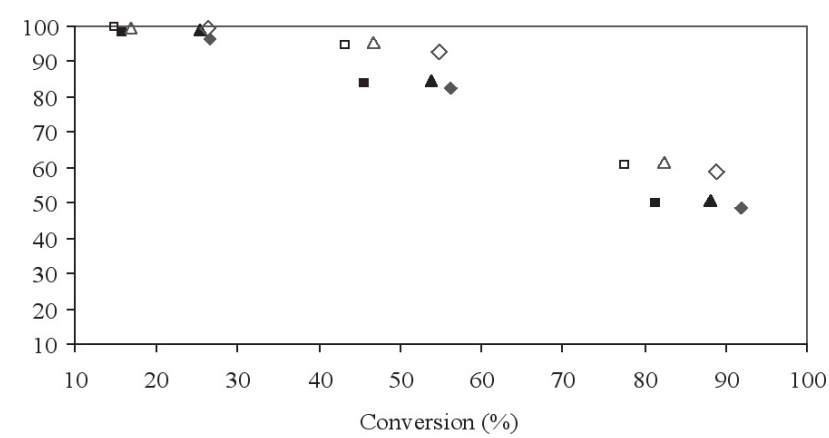

Figure 12: Iso-heptane selectivity vs. n-heptane conversion $\mathrm{WHSV}=3.28$, $\mathrm{n}-\mathrm{H}_{2} / \mathrm{n}-\mathrm{HC}=6$

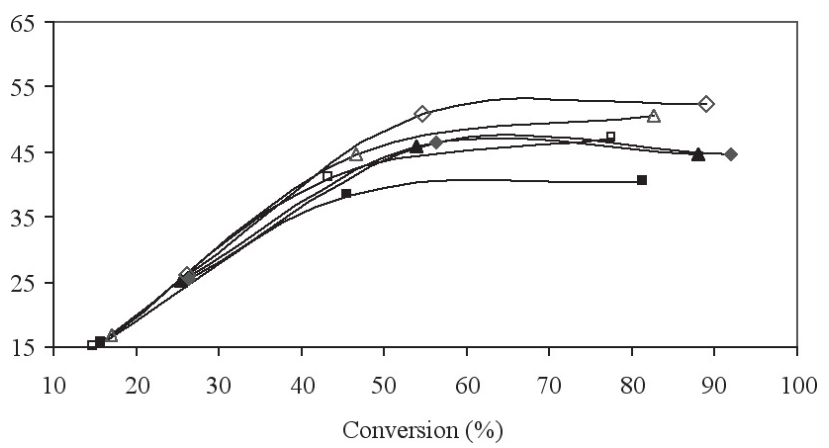

Figure 13: Iso-heptane yield vs. n-heptane conversion WHSV=3.28, n$\mathrm{H}_{2} / \mathrm{n}-\mathrm{HC}=6$

Increasing the reaction temperature to $280^{\circ} \mathrm{C}$ promoted both the n-heptane conversion and the cracking products. However, at higher conversions the iso-heptane selectivity was reduced. On the other hand, lowering the reaction temperature to $230^{\circ} \mathrm{C}$, low n-heptane conversions, reduced the formation of cracking products while, enhanced the iso-heptane selectivity to about $99 \%$. Comparing figures 7, 10 and 13 shows that depending upon the catalyst types the maximum iso-heptane yield occurs at 60 to $80 \%$ of n-heptane conversions. A tail flattening which was observed for iso-heptane yield curve at the feed space velocity of $3.28 \mathrm{~h}^{-1}$, may be attributed to the short contact time of products with acidic sites. The yield of isomers increased sharply at the conversion levels lower than $40 \%$, and leveled off at around 60 to $70 \%$ conversion of n-heptane.

Results indicate that with increasing Pt content, the activity of both types of catalysts having $\mathrm{Si} / \mathrm{Al}=11.65$ and $\mathrm{Si} / \mathrm{Al}=24.5$ is promoted. In case of catalysts with $\mathrm{Si} / \mathrm{Al}=24.5$, iso-heptane selectivity enhanced with increase in Pt content from 0.2 to $0.5 \mathrm{wt} \%$. However selectivity remained unchanged for catalysts containing 0.5 to $1.2 \mathrm{Wt} \%$ of platinum. This is in agreement with Guiesnet et al ${ }^{20}$ data. Such a behavior has been also reported by Pope et al ${ }^{21}$.

As shown in the figures 6,9 and 12 selectivity of isomer products reduced with increase in conversion. This may indicate that $\mathrm{n}$-heptane is first converted into its isomers, and the latter are then cracked to smaller molecules.

Effects of WHSV on n-heptane conversion and iso-heptane selectivity

At a constant reaction temperature, the WHSV parameter was varied by changing the flow of feed components, so that the molar ratio of hydrogen to n-heptane remained unchanged at a value of 6 . n-Heptane conversion and isomer product selectivity as a function of WHSV at $\mathrm{T}=230^{\circ} \mathrm{C}$ is shown in figure. 14. The conversion of n-heptane (solid lines) decreased with increasing WHSV, while the selectivity (dashed lines) of isomers product was extensively increased.

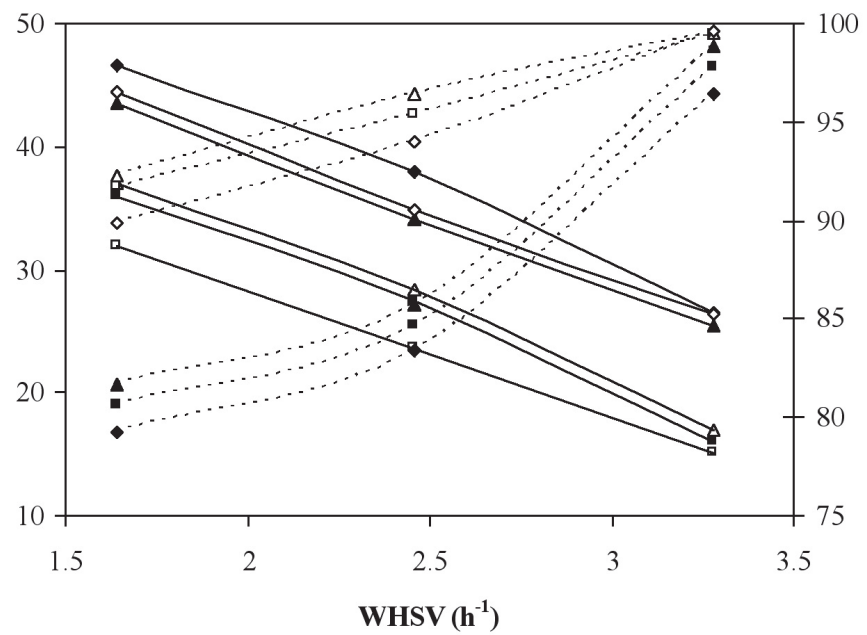

Figure 14: Effect of space velocity on $n$-heptane conversion and isomer selectivity $\mathrm{T}=230 \mathrm{C}, \mathrm{n}-\mathrm{H} 2 / \mathrm{n}-\mathrm{HC}=6$, dashed lines relate to selectivity and solid lines relate to conversion 
Effects of hydrogen to hydrocarbon molar ratio on n-heptane conversion and iso-heptane selectivity

The influence of hydrogen to hydrocarbon molar ratio on $\mathrm{n}$-heptane conversion and iso-heptane selectivity was investigated at $250^{\circ} \mathrm{C}$ and WHSV=1.64. The hydrogen and nitrogen (inert gas), flow rates were adjusted in such a way to keep the WHSV unchanged. As shown in figure 15 , the conversion of $n$-heptane decreased with increasing hydrogen partial pressure, while the selectivity of iso-heptane enhanced. As it is clear from the stoichiometry of the reaction, hydrogen has no role in hydroisomerization but activates the catalyst. The role of hydrogen in promoting isomerization and suppressing the cracking process is attributed to its function in hydrogenation of intermediate olefins in metallic sites (Scheme 2).
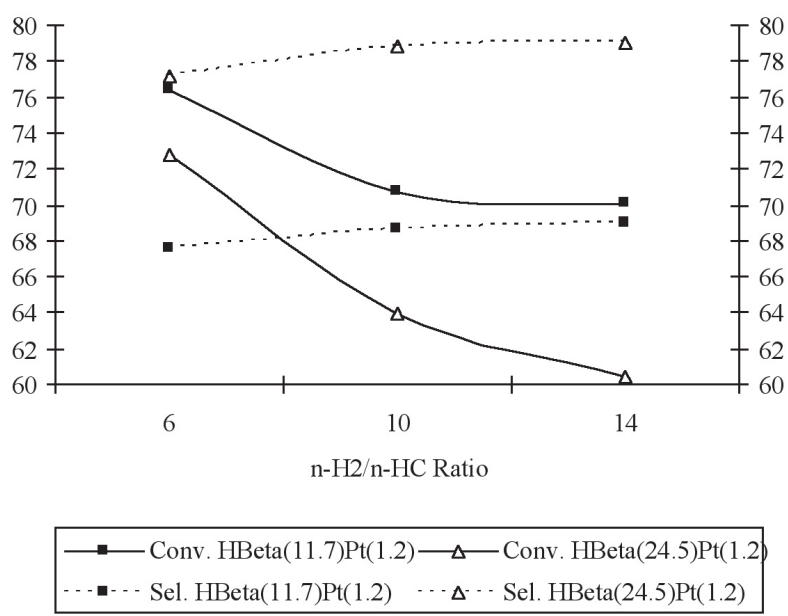

Figure 15: n-Heptane conversion and iso-heptane selectivity vs. hydrogen/ hydrocarbon ratio,

$\mathrm{WHSV}=1.64, \mathrm{~T}=250^{\circ} \mathrm{C}$.

Considering the Weisz mechanism and the above explanation, the following simple reaction scheme could be presented for formation of isomerate and cracking products.

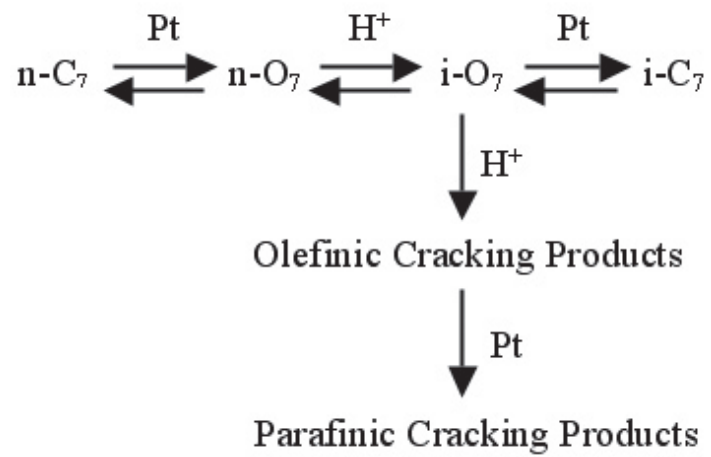

Scheme 2: Simplified mechanism for hydroisomerization reaction on a bifunctional catalyst

Effects of $\mathrm{Si} / \mathrm{Al}$ ratio and metal content on n-heptane conversion and iso-heptane selectivity and yield

As the catalysts activity for isomerization reaction is directly proportional to the metal surface area, it is clear that in case of small metal content, both dehydrogenation and hydrogenation reactions limit the bifunctional process. When the metallic sites are balanced with the acidic sites, such reactions proceed faster than the skeletal isomerization of olefins on the acid sites. This may indicate that under such conditions isomerization is no longer depends on the metal sites. As it is shown in figures 16 and 17 for catalyst with the Si/Al ratio of 24.5 (decreasing acidic sites), the Pt amount required to balance with the acidic sites is reduced. However in case of catalyst with the $\mathrm{Si} / \mathrm{A} 1=11.7$ (increasing acidic sites), more $\mathrm{Pt}$ is necessary to balance with acidic sites.

With a high $\mathrm{Si} / \mathrm{Al}$ ratio, conversion of $\mathrm{n}$-heptane was slightly decreased, but selectivity and yield were promoted. With increasing $\mathrm{Si} / \mathrm{Al}$ ratio, acidic sites density is reduced and consequently the cracking of olefinic intermediate, formed on metallic sites (in the neighborhood of acidic sites), are also decreased. With increasing acidic sites, chances of olefinic intermediates to interact with the latter sites are promoted, while iso-heptane selectivity is decreased.

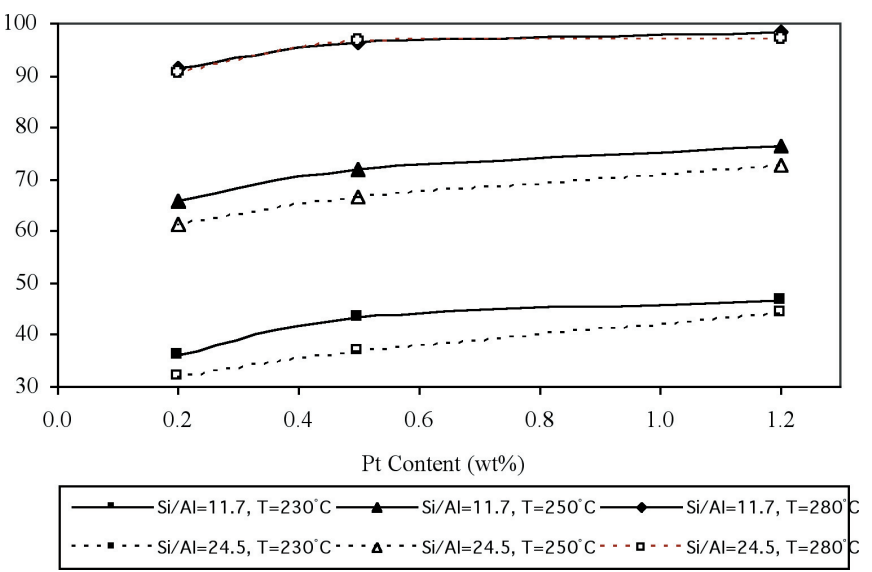
$\mathrm{HC}=6$

Figure 16: $\mathrm{n}-\mathrm{Heptane}$ conversion vs. Pt content, WHSV=1.64, n-H2/n-

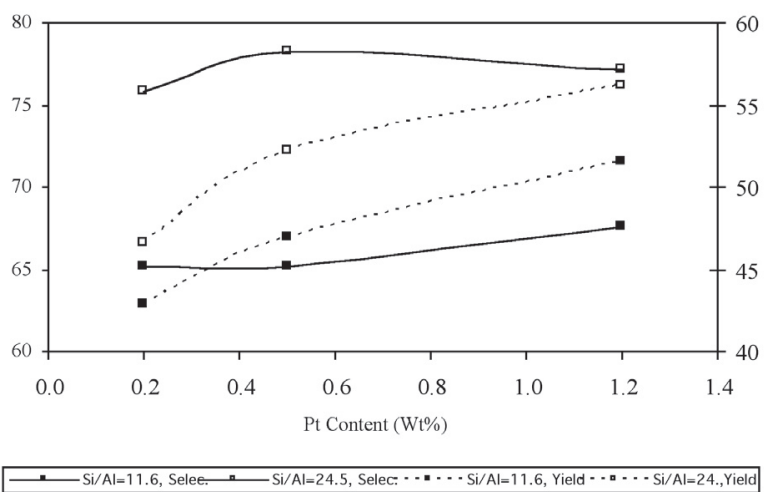

Figure 17: Iso-heptane Selectivity \& Yield vs. Pt content, WHSV=1.64, $\mathrm{n}-\mathrm{H} 2 / \mathrm{n}-\mathrm{HC}=6, \mathrm{~T}=250{ }^{\circ} \mathrm{C}$

\section{Product distribution in n-heptane hydroisomerization}

In table 3 the isomers distribution determined experimentally for 6 catalyst samples are given. $\mathrm{n}$-Heptane isomers distribution under equilibrium condition at $250^{\circ} \mathrm{C}$ are also presented in this table. The n-heptane conversion is far below that of equilibrium value, however the ratios of 2-MC6, 3-MC6, 2,3-DMC5 and 2,4-DMC5 are close to their equilibrium magnitudes due to the rapid methyl shift. n-Heptane was mainly isomerized to 2-MC6 and 3-MC6 with 1 $\sim 1.1$ ratio. 
Table 3. Results for n-heptane catalytic hydroisomerization

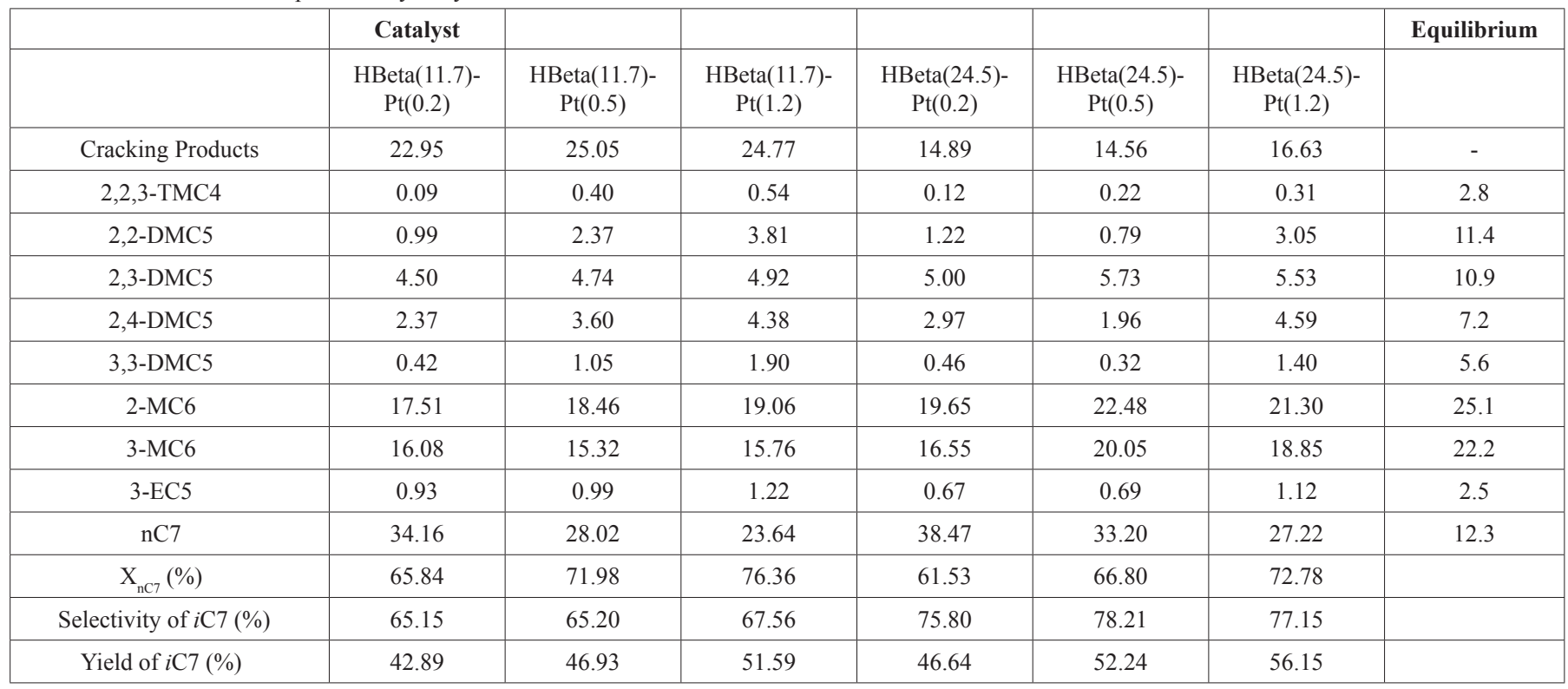

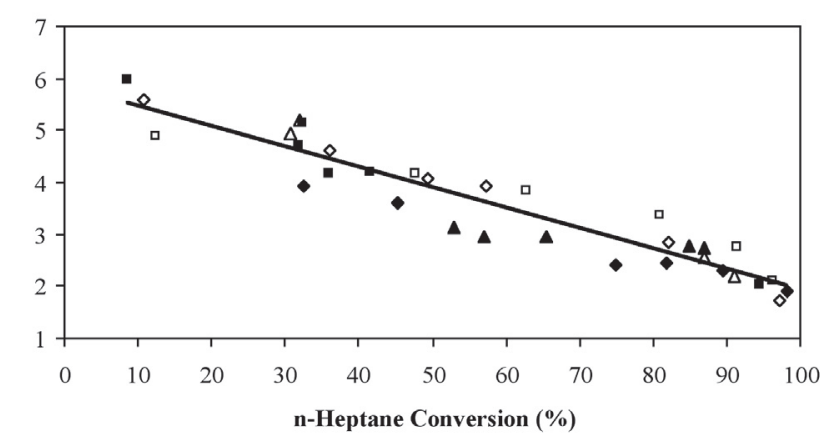

- HBeta(11.7)- $\Delta$ HBeta(11.7)- $\bullet H B e t a(11.7)-\quad$ a HBeta(24.5)- $\Delta$ HBeta(24.5)- $\diamond$ HBeta(24.5)$\begin{array}{llllll}\mathrm{Pt}(0.2 \% \mathrm{wt}) & \mathrm{Pt}(0.5 \% \mathrm{wt}) & \mathrm{Pt}(1.2 \% \mathrm{wt}) & \mathrm{Pt}(0.2 \% \mathrm{wt}) & \mathrm{Pt}(0.5 \% \mathrm{wt}) & \mathrm{Pt}(1.2 \% \mathrm{wt})\end{array}$

Figure 18: Monobranched to dibranched isomer ratio as a function of nheptane conversion under a wide variety of processing conditions. The line represents a linear fit to the data.

In figure 18 the monobranched to dibranched isomers ratio, formed under a wide variety of processing conditions is shown. For these catalysts, the monobranched to dibranched isomers ratio was correlated with a linear function of n-heptane conversion. Such a correlation is valid for different $\mathrm{Si} / \mathrm{Al}$ ratio, metal content, processing temperature and pressure, WHSV and hydrogen to hydrocarbon ratio. Roldan et $a l^{22}$ and Pope et al ${ }^{21}$ have also reported such an isomer distribution. This observation may indicate that in isomerization reactions, the mono-branched isomers are first produced and subsequently changed to multi-branched isomers.

\section{CONCLUSION}

With regard to the experimental results, it is evident that the optimum metal content for $\mathrm{n}$-heptane hydroisomerization catalyst is not a fixed value, but depends upon the $\mathrm{Si} / \mathrm{Al}$ ratio of zeolite. Increasing this ratio, results in a decrease in the catalyst acidity so that the amount of metal required to balance with the acidic sites is accordingly decreased. It has been observed that increasing the metal content from 0.5 to $1.2 \mathrm{wt} \%$ in catalysts with $\mathrm{Si} /$ $\mathrm{Al}=24.5$ have no effect on the selectivity. Increasing the $\mathrm{Si} / \mathrm{Al}$ ratio in catalysts promoted the yield and selectivity, but suppressed the conversion. Among the reaction processing parameter, temperature has the highest effect on the reaction. Increasing the reaction temperature promotes the activity of catalyst while selectivity and isomerate yield are both reduced. Increase in WHSV, decreased $\mathrm{n}$-heptane conversion, but enhanced isomers selectivity. On the other hand, increasing the ratio of hydrogen to hydrocarbon in the feed decreased conversion while, promoted isomers selectivity. The n-heptane conversion is far below that of equilibrium value, however the ratios of 2-MC6, 3-MC6, 2,3-DMC5 and 2,4-DMC5 are close to their equilibrium magnitudes due to the rapid methyl shift. n-Heptane is mainly isomerized to 2-MC6 and 3-MC6 with $1 \sim 1.1$ ratio. This result support the classical bifunctional mechanism in this system rather than PCP (Protonated Cyclopropane) or two molecular mechanisms, proposed by Van Santen et al. ${ }^{10}$ and Leglise ${ }^{23}$, respectively. In addition, the result of $n$-heptane hydroisomerization on $\mathrm{Pt} / \mathrm{H}-\mathrm{Mor}$ catalyst showed that n-heptane is mainly isomerized to 2-MC6 and 3-MC6 with a ratio of $1.1^{24}$ which is in accord with the bifunctional mechanism. For these catalysts, the monobranched to dibranched isomers ratio may be correlated by a linear function of $\mathrm{n}$-heptane conversion. Such a correlation is applied to different $\mathrm{Si} / \mathrm{Al}$ ratio, metal content, processing temperature and pressure, WHSV and hydrogen to hydrocarbon ratio. This observation may indicate that in isomerization reactions, the mono-branched isomers are first produced but subsequently transformed into multi-branched isomers.

\section{ACKNOWLEDGEMENTS}

TEM measurements were performed using the research facilities of the Institute of Electron Optics at the University of Oulu. Prof. A. Chica Lara (Berkley Univ.) and Dr. A. Karegari are gratefully acknowledged for valuable technical assistance. The authors thank Prof. F. Vahabzadeh from Amirkabir University for her assistance in providing certain experimental facilities. 


\section{REFERENCES}

[1] H. Weyda, E. Kohler, Catal. Today, 51, 81, (2003)

[2] R. Le Van Mao, M.A. Saberi, Appl. Catal. A 199, 99, (2000).

[3] A. Chica, A. Corma, P.J. Miguel, Catal. Today, 65, 101, (2001).

[4] J. K. Lee, H. K. Rhee, Catal is Today, 38, 235, (1997).

[5] B.L. Evering, E. L. Douville, A. P. Lien, R. C. Waugh, Ind. \& Eng. Chemistry, 45, 582, (1953)

[6] M. Guisnet, V. Fouche, Appl. Catal. 18, 295, (1991).

[7] M. A. Arribas, F. Márquez, A. Martínez, J. Catal. 190, 309, (2000).

[8] C. Thomazeau, C. Canaff, J. L. Lemberton, M. Guisnet and S. Mignard, Appl. Catal. A 103, 163, (1993).

[9] F. Alvarez, G. Giannetto, M. Guisnet, G. Perot, Appl. Catal. 34, 353, (1987).

[10] A.Van de Runstraat, J. Van Grondelle, R. A. Van Santen, Ind. Eng. Chem. Res. 36, 3116, (1997).

[11] B. Parlitz, E. Schreier, R. Fricke, J. Catal. 155, 1, (1995).

[12] H. L. Zubowa, G. Lischke, B. Parlitz, E. Schreier, R. Eckelt, G. Schulz, R. Fricke, Appl. Catal. A 110, 27, (1994).

[13] Z. B. Wang, A. Kamo, T. Yoneda, T. Komatsu, T. Yashima, Appl. Catal $A, \mathbf{1 5 9}, \mathbf{1 1 9},(1997)$.
[14] E. Blomsma, J. A. Martens, P. A. Jacobs, J. Catal. 159, 323, (1996).

[15] Y. Liu, W. Guo, X.S. Zhao, J. Lian, J. Dou, F. Kooli, J. Porous Mater. 13, 359, (2006).

[16] A. Van de Runstraat, J. Kamp, P.J. Stobbelaar, J. Van Grondelle, S. Krijnen, A. Van Santen, J. Catal. 171, 77, (1997).

[17] E. A. Blekkan, J. C. Pham-Huu, M. J. Ledoux, J. Guillet, Ind. Eng. Chem. Res. 33, 1657, (1994).

[18] Z. Paál, B. Brose, M. Räth, W. Gombler, J. Molec. Catal. 75, 13, (1992).

[19] S.L. Jahn, P.A.P Nascente, D. Cardoso, Zeolite 19, 416, (1997).

[20] F.Riberio, C. Marcilly, M. Guisnet, J. Catal. 78, 267, (1982).

[21] T. D. Pope, J. F. Kriz, M. Stanciulescu, J. Monnier, Appl. Catal A 233, 45, (2003).

[22] R. Roldan, F. J. Romero, C. J. Sanchidrian, J. M. Marinas, J. P. Gomez, Appl. Catal. A 288, 104, (2005).

[23] J. Leglis M. E. Qotbi, D. Cornet, Collect. Czech. Chem. Commun. 57, 882, (1992)

[24] K. Mahos and R. Nakamura, in The Proceedings of the $7^{\text {th }}$ IZC Conference, Elsevier, Tokyo, 1986 ; pp. 973- 978. 